\title{
Development and Validation of a Stability Indicating UPLC Method for Determination of Moxifloxacin Hydrochloride in Pharmaceutical Formulations
}

\section{G. Naveen Kumar Reddy ${ }^{1 *}$, V.V.S.Rajendra Prasad ${ }^{2}$, Nigam Jyoti Maiti ${ }^{3}$, Diptimayee Nayak ${ }^{3}$ and Prashant Kumar Maharana ${ }^{4}$}

${ }^{1}$ Singhania University, Pacheri Bari, Jhunjhunu, Rajasthan

${ }^{2}$ Sitha Institute of Pharmaceutical Sciences, JNTU, Hyderabad

${ }^{3}$ Department of Pharmacy, IMT College of Pharmacy, Puri, Odisha

${ }^{4}$ Mannequin Pharmaceutical, Bhubaneshwar, Odisha

\begin{abstract}
Simple, rapid, sensitive, accurate, robust \& rugged stability indicating analytical method for determination of Moxifloxacin $\mathrm{HCl}$ in pharmaceutical formulations is developed and validated by using UPLC \& applied the developed and validated method for determining the assay of Moxifloxacin $\mathrm{HCl}$ in tablets (Avelox®), as there is no official monograph \& no analytical method by UPLC. Chromatography was performed with mobile phase containing potassium dihydrogen ortho phosphate (adjusted to $\mathrm{pH} 1.8$ with orthophosphoric acid), Methanol \& acetonitrile in the ratio of $60: 20: 20$, with a flow rate of $0.3 \mathrm{~mL} / \mathrm{min}$, C-18 column \& UV detection at $296 \mathrm{~nm}$. The method was validated for linearity, accuracy, ruggedness, robustness, precision \& bench top stability of sample \& standard solution. Moxifloxacin tablets were subjected to different stress conditions like acid, alkali, peroxide, thermal, water \& UV studies and checked for its specificity, degradation \& stability. The developed method was very rapid with a run time of $3 \mathrm{~min}$, accurate, robust, rugged and stable.
\end{abstract}

Keywords: Moxifloxacin; Assay method; UPLC; Stability indicating method

\section{Introduction}

Ultra performance liquid chromatography (UPLC) takes advantage of technological strides made in particle chemistry performance, system optimization, detector design, and data processing and control. Using sub-2 $\mathrm{mm}$ particles and mobile phases at high linear velocities, and instrumentation that operates at higher pressures than those used in HPLC, dramatic increases in resolution, sensitivity, and speed of analysis can be obtained. This new category of analytical separation science retains the practicality and principles of HPLC while creating a step function improvement in chromatographic performance [1].

According to an FDA guidance document, a stability-indicating method is "a validated quantitative analytical procedure that can detect the changes with time in the pertinent properties of the drug substance and drug product. A stability-indicating method accurately measures the active ingredients, without interference from degradation products, process impurities, excipients, or other potential impurities" [2].

Moxifloxacin is slightly yellow crystalline mono-hydrochloride salt [3]. Moxifloxacin Hydrochloride is designated chemically as ((1'S,6'S)-1-Cyclopropyl-7-(2,8-diazabicyclo[4.3.0] non-8-yl)-6fluoro-8-methoxy-4-oxo-1,4-dihydroquinoline-3-carboxylic acid hydrochloride (Figure 1) [4]. Moxifloxacin can be used to treat respiratory infections, including acute sinusitis, acute exacerbations of chronic bronchitis, and community-acquired pneumonia, as well as skin and skin structure infections. Moxifloxacin is also used for the treatment of complicated intra-abdominal infections [5]. Moxifloxacin inhibits bacterial topoisomerase II (DNA gyrase) and topoisomerase IV. Topoisomerases are essential enzymes which play a crucial role in the replication and repair of bacterial DNA. This mechanism is lethal to susceptible bacteria. Moxifloxacin is often referred to as a chemotherapeutic drug because its mode of action has so far not been noted in any naturally occurring or semi-synthetic antibiotic.
A few methods for the determination of Moxifloxacin Hydrochloride in pharmaceutical formulations by HPLC [6], HPTLC [3] and UV [7] appear in literature. So far no systematic UPLC method has been reported for determination of Moxifloxacin Hydrochloride in pharmaceutical formulations. This paper reports a rapid and sensitive UPLC method with UV detection, useful for routine quality control of Moxifloxacin Hydrochloride in pharmaceutical formulations. The method was validated by parameters such as linearity, accuracy, precision, robustness, ruggedness, sample and standard solution stability and forced degradation studies.

\section{Experimental}

\section{Reagents}

HPLC grade Acetonitrile (HPLC Grade, Merck), Potassium dihydrogen orthophosphate (AR, Rankem), Hydrochloric Acid (AR, Rankem) Sodium hydroxide (AR, Rankem), Hydrogen peroxide (AR, Rankem), Ortho phosphoric acid (AR,Rankem),Water (Milli Q water), Acetonitrile (HPLC Grade, Merck). Moxifloxacin pure drug substance was kindly supplied by MSN Laboratories Limited, India. Ingredients used for placebo were microcrystalline cellulose, croscarmellose sodium, PVPK-30, Ethanol, Magnesium stearate.

*Corresponding author: G. Naveen Kumar Reddy, Singhania University, Pacheri Bari, Jhunjhunu, Rajasthan, Tel: +91996340443; E-mail: naving29@ gmail.com

Received November 03, 2011; Accepted November 18, 2011; Published November 21, 2011

Citation: Naveen Kumar Reddy G, Rajendra Prasad VVS, Maiti NJ, Nayak D, Prashant Kumar M (2011) Development and Validation of a Stability Indicating UPLC Method for Determination of Moxifloxacin Hydrochloride in Pharmaceutical Formulations. Pharm Anal Acta 2:142. doi:10.4172/2153-2435.1000142

Copyright: (c) 2011 Naveen Kumar Reddy G, et al. This is an open-access article distributed under the terms of the Creative Commons Attribution License, which permits unrestricted use, distribution, and reproduction in any medium, provided the original author and source are credited. 
Citation: Naveen Kumar Reddy G, Rajendra Prasad VVS, Maiti NJ, Nayak D, Prashant Kumar M (2011) Development and Validation of a Stability Indicating UPLC Method for Determination of Moxifloxacin Hydrochloride in Pharmaceutical Formulations. Pharm Anal Acta 2:142. doi:10.4172/2153-2435.1000142

\section{Instrumentation}

A liquid chromatography (Waters Acquity) system equipped with an injection valve (Rheodyne) \& PDA detector. The UPLC system was well equipped with Empower 2 software for data processing. Other<smiles>COc1c(N2CC3CCCNC3C2)c(F)cc2c(=O)c(C(=O)O)cn(C3CC3)c12</smiles>

Figure 1: Moxifloxacin Hydrochloride.

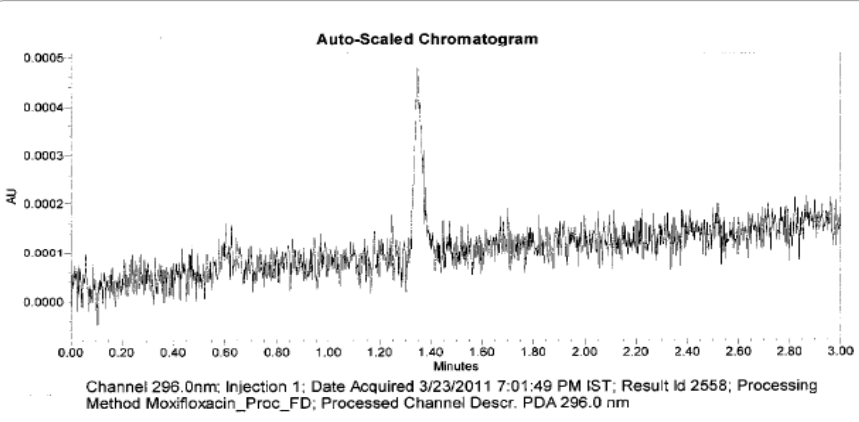

Figure 2: Blank-Diluent.

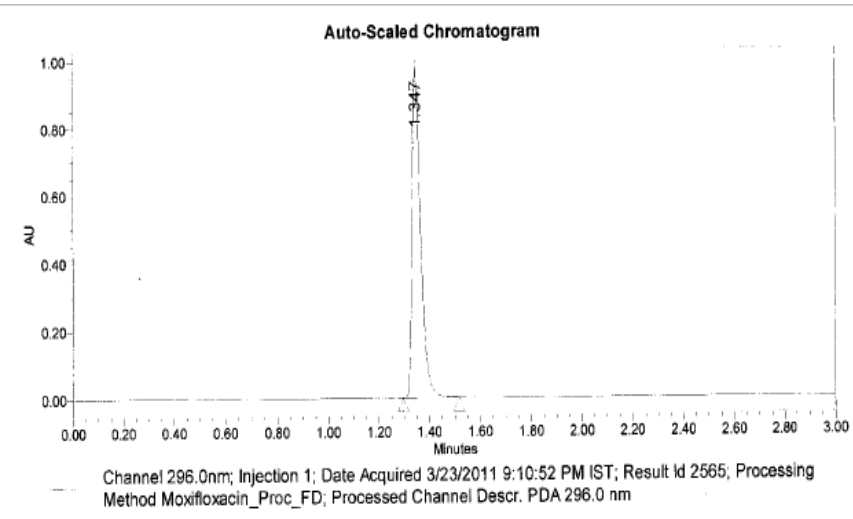

Figure 3: Standard.

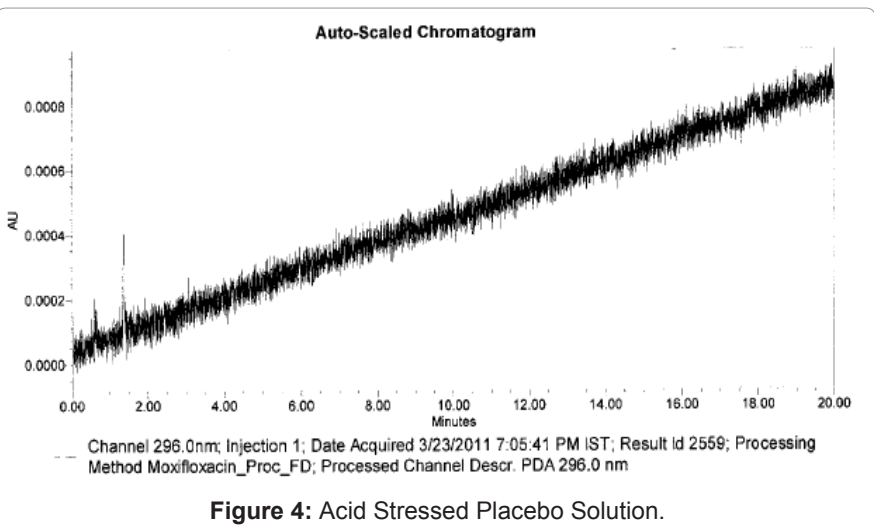

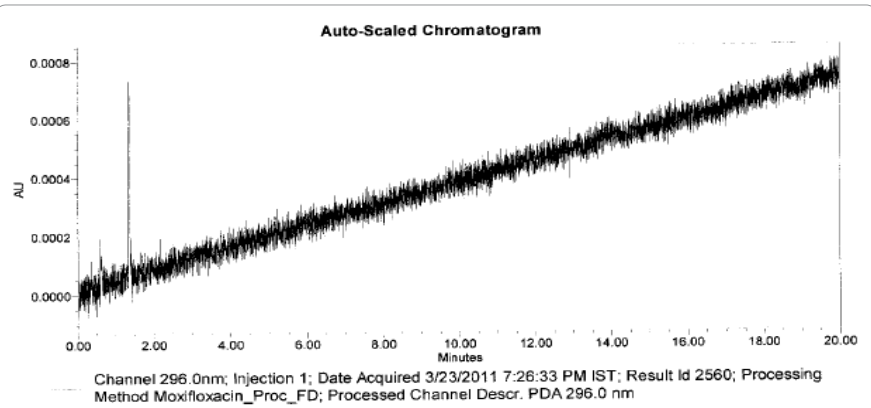

Figure 5: Alkali Stressed Placebo.
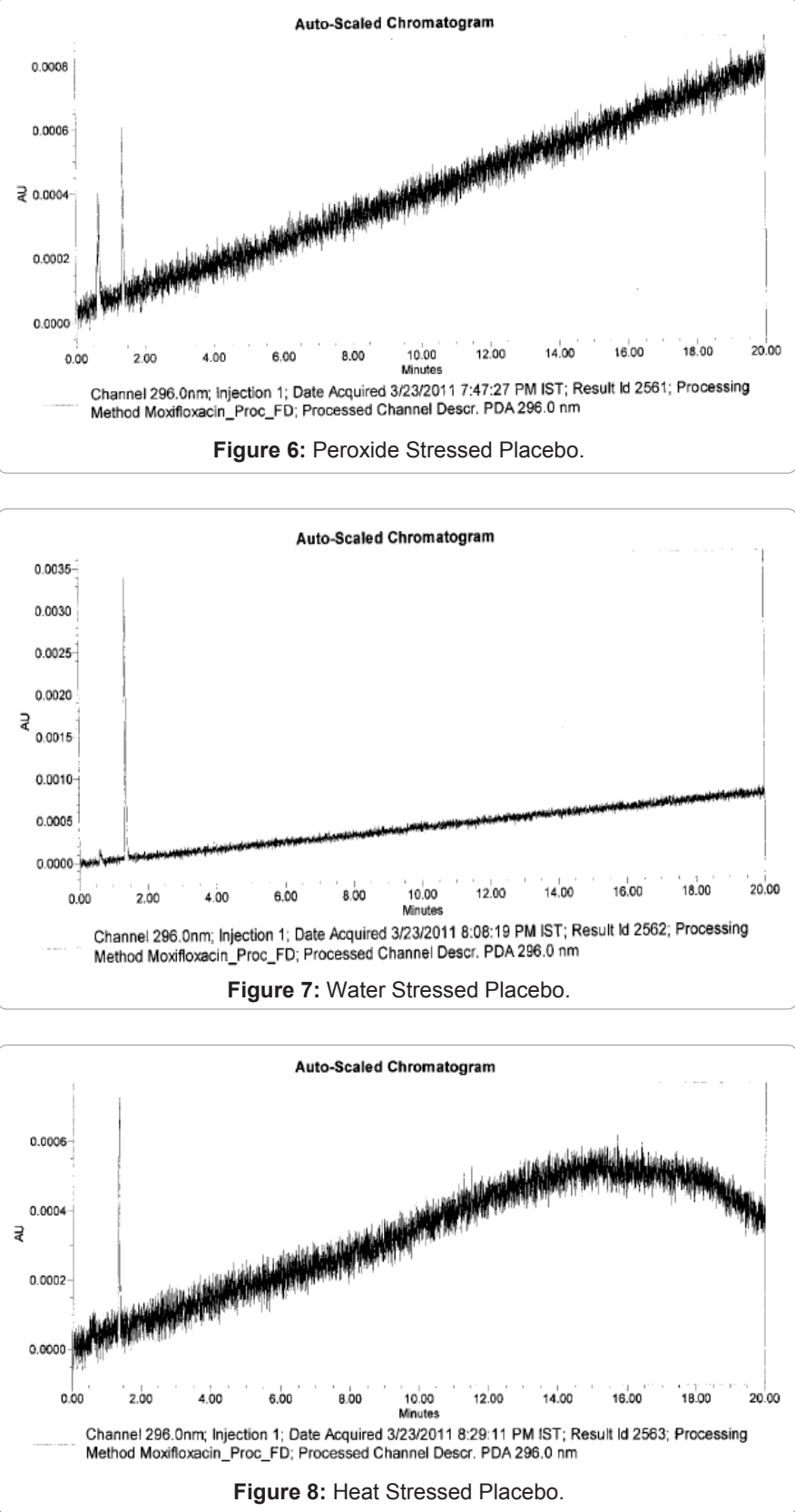

instruments like Sartorius Analytical Balance, Metrohm pH Meter and Biotechnics sonicator were used in sample and standard preparations 
Citation: Naveen Kumar Reddy G, Rajendra Prasad VVS, Maiti NJ, Nayak D, Prashant Kumar M (2011) Development and Validation of a Stability Indicating UPLC Method for Determination of Moxifloxacin Hydrochloride in Pharmaceutical Formulations. Pharm Anal Acta 2:142. doi:10.4172/2153-2435.1000142

and for forced degradation studies.

\section{Methodology}

\section{Chromatographic conditions}

The analytical column used was Waters HSS, C-18, 100X2.1; $1.8 \mu \mathrm{m}$.The mobile phase was potassium dihydrogen ortho phosphate, adjusted to $\mathrm{pH} 1.8$ with ortho phosphoric acid, methanol \& acetonitrile in the ratio of $60: 20: 20$. It has a flow rate of $0.3 \mathrm{~mL} / \mathrm{min}$, injection volume of $1 \mu \mathrm{L}$ with ambient column oven temperature and sample tray temperature with isocratic elution \& UV detection at $296 \mathrm{~nm} \&$ a run time of $3 \mathrm{~min}$.

\section{Standard, sample, mobile phase and diluent preparation}

Diluent: Mobile phase is used as diluent:

Preparation of mobile phase: Dissolved $3.4 \mathrm{~g}$ of potassium dihydrogen ortho phosphate in one litre water and adjusted the $\mathrm{pH}$ to

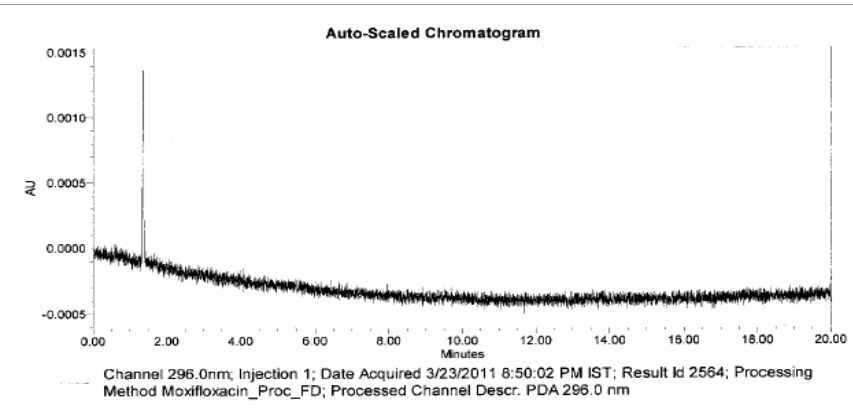

Figure 9: UV Stressed Placebo.
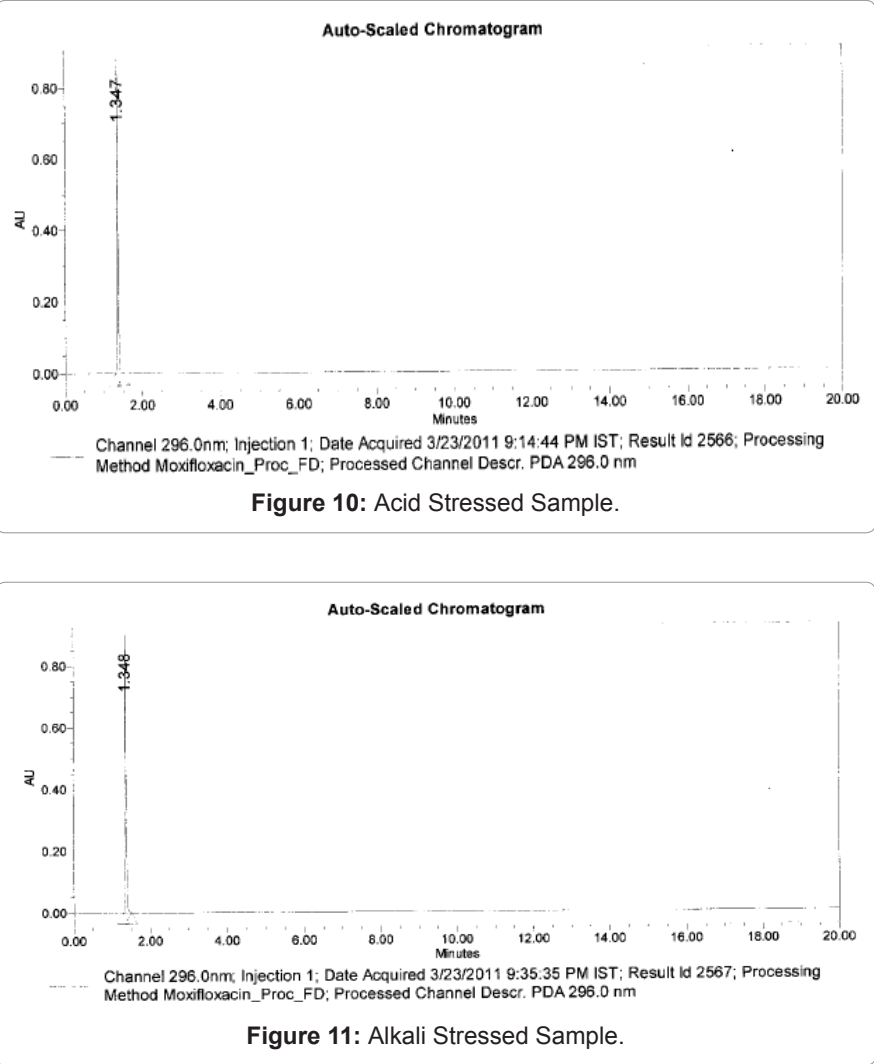

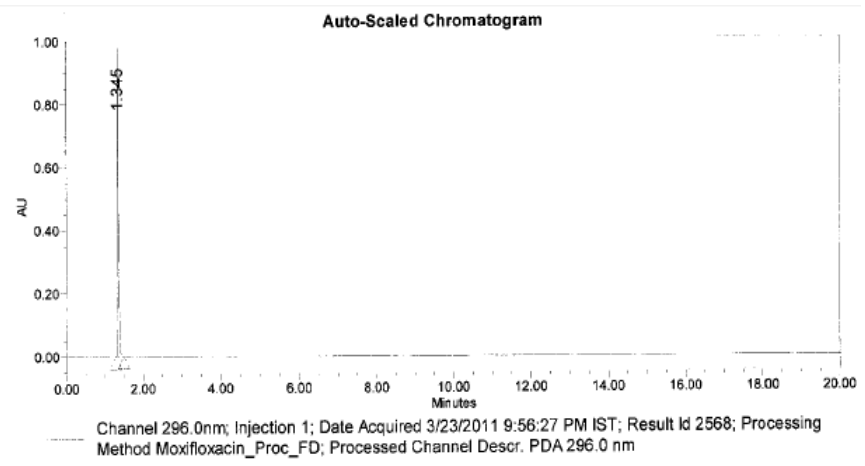

Figure 12: Peroxide Stressed Sample.

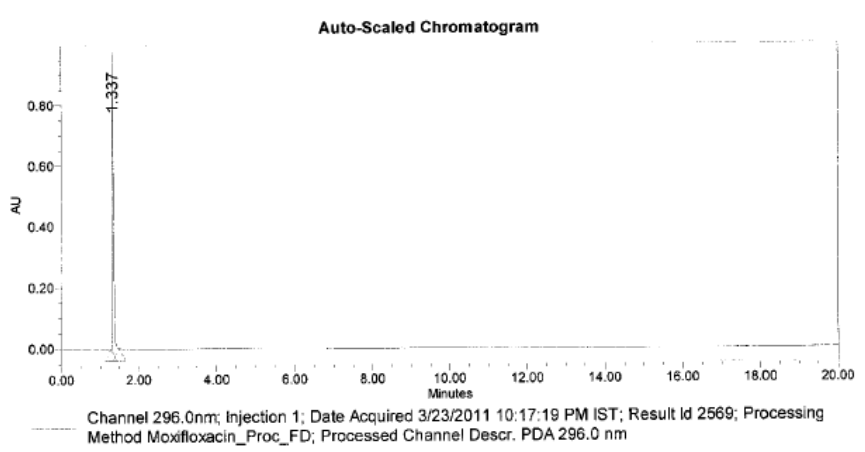

Figure 13: Water Stressed Sample.
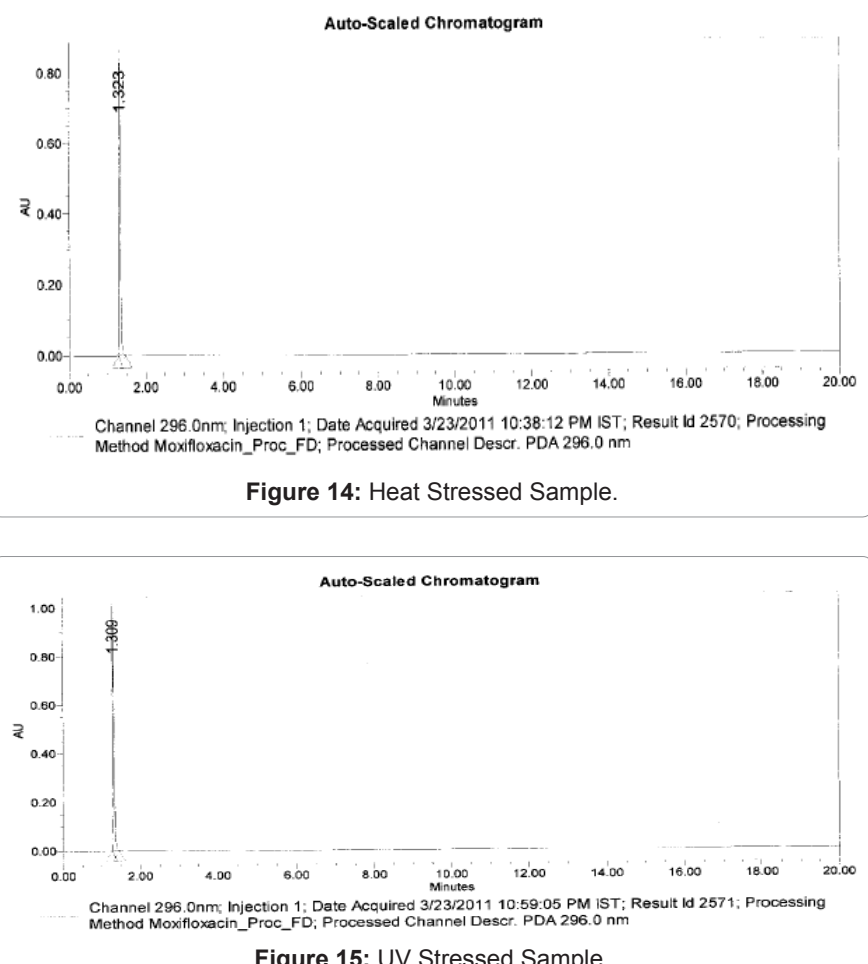

1.8 with ortho phosphoric acid.Filtered through $0.22 \mu$ membrane filter. Mixed the buffer,acetonitrile and methanol in the ratio of 60:20:20 and sonicated to degas. 
Citation: Naveen Kumar Reddy G, Rajendra Prasad VVS, Maiti NJ, Nayak D, Prashant Kumar M (2011) Development and Validation of a Stability Indicating UPLC Method for Determination of Moxifloxacin Hydrochloride in Pharmaceutical Formulations. Pharm Anal Acta 2:142. doi:10.4172/2153-2435.1000142

Page 4 of 10

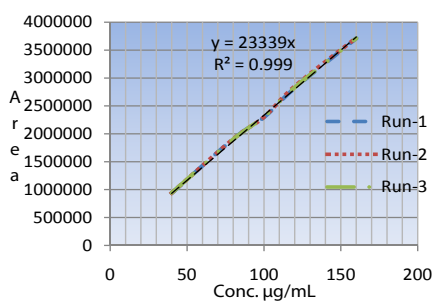

Figure 16: Linearity.

Preparation of standard solution: Accurately weighed and transferred $44 \mathrm{mg}$ of Moxifloxacin $\mathrm{HCl}$ in to a $100 \mathrm{~mL}$ volumetric flask and added $70 \mathrm{~mL}$ of diluent.Sonicated for $5 \mathrm{~min}$ and made up to the mark with diluent.Transferred $5 \mathrm{~mL}$ of above solution to $20 \mathrm{~mL}$ volumetric flask and made up to volume with diluent. Filtered with $0.45 \mu \mathrm{m}$ PFTE filter.

Preparation of Test solution: Weighed 20 tablets(Avelox-400mg) manufactured by Bayer Health Care AG, Germany and determined the average weight.Weighed 2 tablets and transferred in to a $200 \mathrm{~mL}$ volumetric flask and added $150 \mathrm{~mL}$ of diluent.Sonicated in cold water for 20minutes with intermittent shaking.Allowed it to cool to room temperature and diluted to volume with diluent. Filtered atleast $12 \mathrm{~mL}$ of the above solution with $0.45 \mu \mathrm{m}$ PTFE filter and transfered $5 \mathrm{~mL}$ of filtered solution to $200 \mathrm{~mL}$ volumetric flask and made up to volume with diluent.

\section{Method development}

By selecting the HPLC method conditions from literature and by using the UPLC method convertor calculated the chromatographic conditions.

Wavelength was selected at $296 \mathrm{~nm}$ based on the literature [6] and by scanning with PDA detector.
$\mathrm{pH}$ of the buffer was selected based on its $\mathrm{pKa}$ value.

Taken 0.05M Potassium di hydrogen phosphate and adjusted the $\mathrm{pH}$ to $1.8 \pm 0.05$ with OPA. By using buffer and ACN: $\mathrm{MeOH}(600: 400)$ and by using the gradient programmes mentioned as in (Table 1) with HSS C-18,100X2.1,1.8 $\mu \mathrm{m}$ column, flow rate of $0.3 \mathrm{~mL} / \mathrm{min}$, injection volume $(5 \mu \mathrm{l})$,column oven temperature at $25^{\circ} \mathrm{C}$ injected the Moxifloxacin $\mathrm{HCl}$ standard.

In Trial -1 a split peak was observed at a retention time $34 \mathrm{~min}$, which might be because of more buffer. So changed the gradient programme with less buffer and more organic solvents as in Trial -2, in this case the peak was little broad and the retention time decreased to $7 \mathrm{~min}$.Then decreased the buffer as mentioned in Trial-3 and with that gradient programme and with an injection volume of $1 \mu \mathrm{L}$ injected Moxifloxacin $\mathrm{HCl}$ standard. In this it eluted at 3.2RT and the peak shape was good.

By considering all the aspects went for an isocratic elution with Buffer : (ACN: MeOH) 600:400 and with the above mentioned chromatographic conditions injected standard and test solutions. Peak shape, theoretical plates, RSD and tailing all were fine and within the limits.

\section{Results and Discussion}

\section{Specificity}

Specificity is the ability to assess unequivocally the analyte in the presence of components which may be expected to be present. Typically these might include impurities, degradants, matrix, etc. [8]. Specificity was demonstrated by injecting a blank, placebo and standard solution. No interference was seen at the retention time of analyte. The specificity was also demonstrated by induced degradation of Moxifloxacin formulation and placebo samples to acid degradation, alkali degradation, peroxide degradation, thermal degradation, water degradation, U.V. degradation. Purity angle is less than purity

\begin{tabular}{|c|c|c|c|c|c|c|c|c|}
\hline \multicolumn{3}{|l|}{ Trial-1 } & \multicolumn{3}{|l|}{ Trial-2 } & \multicolumn{3}{|c|}{ Trial-3 } \\
\hline Time & Buffer $\% A$ & ACN:MeOH \% B & Time & Buffer $\% A$ & $\mathrm{ACN}: \mathrm{MeOH} \% \mathrm{~B}$ & Time & Buffer $\% A$ & ACN:MeOH \% B \\
\hline 0.00 & 100 & 0 & 0.00 & 85 & 15 & 0.00 & 70 & 30 \\
\hline 10.00 & 95 & 5 & 10.00 & 85 & 15 & 3.50 & 70 & 30 \\
\hline 15.00 & 85 & 15 & 15.00 & 57 & 46 & 4.50 & 30 & 70 \\
\hline 30.00 & 70 & 30 & 30.00 & 56 & 44 & 5.50 & 70 & 30 \\
\hline 40.00 & 40 & 60 & 40.00 & 30 & 70 & 7.00 & 70 & 30 \\
\hline 345.00 & 100 & 0 & 45.00 & 85 & 15 & & & \\
\hline 50.00 & 100 & 0 & 50.00 & 85 & 15 & & & \\
\hline
\end{tabular}

Table 1:

\begin{tabular}{|l|l|l|l|l|}
\hline MOXIFLOXACIN FORCED DEGRADATION & \multicolumn{3}{l|}{} \\
\hline Stress Condition & Reagent Used & Conc. & Purity Angle \\
\hline Acid Stress & $\mathrm{HCl}$ & $0.1 \mathrm{~N}$ & 0.120 & 0.271 \\
\hline Alkali Stress & $\mathrm{NaOH}$ & $0.1 \mathrm{~N}$ & 0.124 & 0.274 \\
\hline Peroxide Stress & $\mathrm{H}_{2} \mathrm{O}_{2}$ & $3 \%$ & 0.138 & 0.140 \\
\hline Water Stress & Water & & 0.118 & 0.277 \\
\hline Heat Stress & Heater & $60^{\circ} \mathrm{C}$ & 0.272 \\
\hline U.V. Stress & Photolytic chamber & 1 Week & 0.170 \\
\hline Acceptance Criteria & Peak Purity shall pass & & 0.278 \\
\hline
\end{tabular}

Table 2: 
Citation: Naveen Kumar Reddy G, Rajendra Prasad VVS, Maiti NJ, Nayak D, Prashant Kumar M (2011) Development and Validation of a Stability Indicating UPLC Method for Determination of Moxifloxacin Hydrochloride in Pharmaceutical Formulations. Pharm Anal Acta 2:142. doi:10.4172/2153-2435.1000142

Page 5 of 10

threshold for all the stress conditions. The results are tabulated in (Table 2), (Figures 2-15) represents different stress conditions.

\section{System suitability Testing}

System suitability testing is used to verify that the reproducibility of the system is adequate for the analysis to be performed. System suitability is done by preparing and injecting the standard solution 5 times and calculating its RSD. Other parameters like tailing and theoretical plates should also be taken in to consideration. Results are tabulated in (Table 3).

\section{Linearity}

The linearity of an analytical procedure is its ability (within a given range) to obtain test results which are directly proportional to the concentration (amount) of analyte in the sample [8]. The linearity of the test method was performed by plotting a graph between concentration of the test solution on $\mathrm{X}$-axis and response of the corresponding solutions on $\mathrm{Y}$-axis from $40 \%$ to $160 \%$ of test concentration and calculated the correlation coefficient, it was found to be 0.999 .The results are tabulated in (Table $4 \& 5$ ) and the graphs are represented as Figure 16

\section{Limit of detection (LOD) and limit of quantification (LOQ)}

The detection limit of an individual analytical procedure is the lowest amount of analyte in a sample which can be detected but not necessarily quantitated as an exact value. The quantitation limit of an individual analytical procedure is the lowest amount of analyte in a sample which can be quantitatively determined with suitable precision and accuracy [8]. Calculated the LOD \& LOQ, with the calculations obtained from evaluation of the calibration curve of the linearity. LOD and LOQ values are less than the minimum linearity concentration.

The calculations and results are tabulated in (Table 6).

\section{Bench top stability of standard \& test preparation}

Performed the assay of Moxifloxacin as per the test method in duplicate and kept the standard and test solutions on the bench top for $48 \mathrm{Hrs}$. Injected at initial, $24 \mathrm{Hrs}$. and $48 \mathrm{Hrs}$. Calculated the difference between initial and bench top stability samples for $\%$ assay of Moxifloxacin for test solutions and similarity factor for standard solutions were found to be within limits. The results are tabulated in (Table 7).

\section{Accuracy}

The accuracy of an analytical procedure expresses the closeness of agreement between the value which is accepted either as a conventional true value or an accepted reference value and the value found [8] Performed the accuracy of test method using Moxifloxacin placebo at $50 \%, 70 \%, 100 \%, 125 \%, 150 \%$ spike levels. The $\%$ assay at each spike level was found to be between $98.0-102.0 \%$ of the labeled amount. The results are tabulated in (Table 8 and 9).

\section{Precision}

The precision of an analytical procedure expresses the closeness of agreement (degree of scatter) between a series of measurements obtained from multiple sampling of the same homogeneous sample under the prescribed conditions. Precision may be considered at three levels: repeatability, intermediate precision and reproducibility [8].

\section{Method precision}

Determined the precision of the test method by preparing \& injecting 6 test solutions of Moxifloxacin formulations in to the chromatograph and recorded the results. The average \% assay was found to be 100.4 with \% RSD of 0.62 . The results are tabulated in (Table 10).

\section{Intermediate precision}

Performed the assay of Moxifloxacin by following the same procedure as that of Method precision but on a different day and by a different analyst. The average $\%$ assay was found to be $99.4 \%$ with \% RSD of 0.39 .Overall RSD when compared with Method precision is 0.73. The results are tabulated in (Table 11 and 12).

\begin{tabular}{|c|c|c|c|c|c|c|c|c|c|}
\hline \multicolumn{10}{|c|}{ Moxifloxacin System Suitability } \\
\hline Injection No.: & 1 & 2 & 3 & 4 & 5 & Mean & STDEV & RSD & Limits \\
\hline Standard Area: & 2305687 & 2302824 & 2311478 & 2300543 & 2283295 & 2300765 & 10589 & 0.5 & RSD NMT $2.0 \%$ \\
\hline Theoretical Plates & 7818 & 7835 & 7825 & 7826 & 7829 & 7827 & 6.19 & 0.1 & NLT 2000 \\
\hline USP tailing & 1.54 & 1.54 & 1.54 & 1.54 & 1.53 & 1.54 & 0.00 & 0.3 & NMT 2.0 \\
\hline RT & 1.259 & 1.260 & 1.263 & 1.265 & 1.267 & 1.263 & 0.00 & 0.3 & \\
\hline
\end{tabular}

Table 3 :

\begin{tabular}{|c|c|c|c|c|c|}
\hline \multirow{2}{*}{$\begin{array}{l}\text { Moxifloxacin } \\
\text { Weighed }\end{array}$} & \multirow{2}{*}{$\begin{array}{l}\text { Equivalent } \\
\text { to } \mathrm{mg}\end{array}$} & \multicolumn{4}{|c|}{ MOXIFLOXACIN-LINEARITY } \\
\hline & & Diluted to $(\mathrm{mL})$ & $\mathrm{mL}$ & $\mathrm{mL}$ & Conc. $(\mu \mathrm{g} / \mathrm{mL})$ \\
\hline 43.64 & 40.02 & 100 & 2 & 20 & 40.02 \\
\hline 43.64 & 40.02 & 100 & 4 & 20 & 80.04 \\
\hline 43.64 & 40.02 & 100 & 5 & 20 & 100.04 \\
\hline 43.64 & 40.02 & 100 & 6 & 20 & 120.05 \\
\hline 43.64 & 40.02 & 100 & 8 & 20 & 160.07 \\
\hline
\end{tabular}

Table 4 : 
Citation: Naveen Kumar Reddy G, Rajendra Prasad VVS, Maiti NJ, Nayak D, Prashant Kumar M (2011) Development and Validation of a Stability Indicating UPLC Method for Determination of Moxifloxacin Hydrochloride in Pharmaceutical Formulations. Pharm Anal Acta 2:142. doi:10.4172/2153-2435.1000142

Page 6 of 10

\begin{tabular}{|c|c|c|c|c|c|c|}
\hline \multicolumn{7}{|c|}{ MOXIFLOXACIN-LINEARITY } \\
\hline Run & $\%$ Conc. & $\begin{array}{l}\text { Conc. Of } \\
\text { Moxifloxacin }(\mu \mathrm{g} / \mathrm{mL})\end{array}$ & $\begin{array}{l}\text { Area of } \\
\text { Moxifloxacin }\end{array}$ & Slope & Y-intercept & $\mathbf{R}^{2}$ \\
\hline \multirow{5}{*}{1} & $40 \%$ & 40.02 & 937722 & \multirow{5}{*}{23058.3} & \multirow{5}{*}{27292.95} & \multirow{5}{*}{0.995} \\
\hline & $80 \%$ & 80.04 & 1908256 & & & \\
\hline & $100 \%$ & 100.04 & 2295800 & & & \\
\hline & $120 \%$ & 120.05 & 2819056 & & & \\
\hline & $160 \%$ & 160.07 & 3709937 & & & \\
\hline \multirow{5}{*}{2} & $40 \%$ & 40.02 & 942173 & \multirow{5}{*}{23183.8} & \multirow{5}{*}{25535.15} & \multirow{5}{*}{0.999} \\
\hline & $80 \%$ & 80.04 & 1908189 & & & \\
\hline & $100 \%$ & 100.04 & 2301865 & & & \\
\hline & $120 \%$ & 120.05 & 2852614 & & & \\
\hline & $160 \%$ & 160.07 & 3719921 & & & \\
\hline \multirow{5}{*}{3} & $40 \%$ & 40.02 & 943469 & \multirow{5}{*}{23069.1} & \multirow{5}{*}{31258.15} & \multirow{5}{*}{0.999} \\
\hline & $80 \%$ & 80.04 & 1902911 & & & \\
\hline & $100 \%$ & 100.04 & 2306901 & & & \\
\hline & $120 \%$ & 120.05 & 2831549 & & & \\
\hline & $160 \%$ & 160.07 & 3711182 & & & \\
\hline \multicolumn{4}{|c|}{ Average } & 23103.74846 & 28028.75 & 0.999 \\
\hline \multicolumn{4}{|c|}{ Standard Deviation } & 69.55 & 2931.59 & 0.00 \\
\hline
\end{tabular}

Table 5:

Moxifloxacin- Limit of detection (LOD) \& Limit of Quantification (LOQ)

\begin{tabular}{|c|c|c|c|c|}
\hline \multicolumn{5}{|c|}{ Moxifloxacin- Limit of detection (LOD) \& Limit of Quantification (LOQ) } \\
\hline S.No. & Injection No. & Slope & Y-Intercept & $\mathrm{R}^{2}$ \\
\hline 1 & Inj-1 & 23059.4 & 27156.504 & 0.999 \\
\hline 2 & Inj-2 & 23184.9 & 25399.4381 & 0.999 \\
\hline 3 & Inj-3 & 23070.2 & 31121.98583 & 0.998 \\
\hline \multicolumn{2}{|c|}{ Average } & 23104.8333 & 27892.6426 & 0.9987 \\
\hline \multicolumn{2}{|l|}{ STDEV } & 69.550 & 2931.435 & 0.001 \\
\hline \multicolumn{5}{|c|}{$\mathrm{LOD}=3.3 \times \sigma / \mathrm{S}$} \\
\hline LOD & 0.4 & ppm & & \\
\hline \multicolumn{5}{|c|}{$L O Q=10 \times \sigma / S$} \\
\hline \multicolumn{5}{|c|}{$\sigma=$ Standard deviation of $y$-intercepts of regression line } \\
\hline \multicolumn{5}{|c|}{$S=$ slope of the linearity curve } \\
\hline LOQ & 1.3 & ppm & & \\
\hline
\end{tabular}

Acceptance Criteria: LOD \& LOQ values shall be less than the minimum linearity concentration

Table 6:

\section{Robustness}

The robustness of an analytical procedure is a measure of its capacity to remain unaffected by small, but deliberate variations in method parameters and provides an indication of its reliability during normal usage [8]. Robustness was performed by injecting the Moxifloxacin standard solution in to the UPLC by altering the Flow rate, Column oven temperature and also by changing the $\mathrm{pH}$ of the buffer \& composition of the organic solvent from the normal 
Citation: Naveen Kumar Reddy G, Rajendra Prasad VVS, Maiti NJ, Nayak D, Prashant Kumar M (2011) Development and Validation of a Stability Indicating UPLC Method for Determination of Moxifloxacin Hydrochloride in Pharmaceutical Formulations. Pharm Anal Acta 2:142. doi:10.4172/2153-2435.1000142

Page 7 of 10

\begin{tabular}{|c|c|c|c|c|c|c|}
\hline \multicolumn{7}{|c|}{ Moxifloxacin Bench Top Stability of Standard Solution } \\
\hline Time(Hrs) & Day & Std. Wt. & Response & Fresh Std Wt. & $\begin{array}{l}\text { Response of } \\
\text { fresh std. }\end{array}$ & $\begin{array}{l}\text { Similarity } \\
\text { Factor }\end{array}$ \\
\hline Initial & Initial & 44.02 & 2300765 & & & \\
\hline $24 \mathrm{Hrs}$ & Day-1 & 44.02 & 2311082 & 44.13 & 2316978 & 1 \\
\hline $48 \mathrm{Hrs}$ & Day-2 & 44.02 & 229288 & 43.89 & 2268919 & 0.99 \\
\hline
\end{tabular}

Acceptance Limits: Similarity Factor should be NMT 2.0

Moxifloxacin Bench Top Stability of Test Solution-1

\begin{tabular}{|l|l|l|l|l|l|l|}
\hline Time(Hrs) & Day & Weight(mg) & Response of sample & \% Assay & Difference from Initial \\
\hline Initial & Initial & 1353.34 & 2337254 & 101.29 & NA \\
\hline $24 \mathrm{Hrs}$ & Day-1 & 1353.34 & 2331881 & 100.6 & 0.7 \\
\hline $48 \mathrm{Hrs}$ & Day-2 & 1353.34 & 2305445 & 101.01 & 0.3 \\
results of Initial,24 \& 48 \\
Hrs shall be NMT 2.0
\end{tabular}

Moxifloxacin Bench Top Stability of Test Solution-2

\begin{tabular}{|l|l|l|l|l|l|}
\hline Time(Hrs) & Day & Weight(mg) & Response of sample & \% Assay & Difference from Initial \\
\hline Initial & Initial & 1351.89 & 2321427 & 100.6 & NA \\
\hline 24 Hrs & Day-1 & 1351.89 & 2320794 & 100.12 & 0.5 \\
\hline $48 \mathrm{Hrs}$ & Day-2 & 1351.89 & 2327728 & 101.99 & 1.4 \\
\hline
\end{tabular}

Table 7:

\begin{tabular}{|c|c|c|c|c|c|c|c|}
\hline Standard Preparation & 44.13 & mg & 5 & Potency & 98.8 & & \\
\hline & & & & & & Molecular factor & \\
\hline \multirow{2}{*}{ Sample Preparation } & \multicolumn{2}{|c|}{ Wt. of sample taken in $\mathrm{mg}$} & 5 & Label Claim & 400 & of Moxifloxacin & 0.917 \\
\hline & 200 & & 200 & & & & \\
\hline \multicolumn{2}{|l|}{ Standard Area } & 2316978 & & Average Wt. in $\mathrm{mg}$ & & 675.01 & \\
\hline
\end{tabular}

Table 8:

\section{MOXIFLOXACIN-ACCURACY}

\begin{tabular}{|c|c|c|c|c|c|c|c|}
\hline $\begin{array}{l}\text { Spike } \\
\text { level }\end{array}$ & $\begin{array}{l}\text { Wt.of sample } \\
\text { taken in mg }\end{array}$ & $\begin{array}{l}\text { Sample } \\
\text { area }\end{array}$ & $\begin{array}{l}\mathrm{mg} / \mathrm{mL} \\
\text { added }\end{array}$ & $\begin{array}{l}\mathrm{mg} / \mathrm{mL} \\
\text { found }\end{array}$ & $\%$ Recovery & $\%$ Recovery & Average \\
\hline 50\%_01 & 674.46 & 1159290 & 0.04996 & 0.05454 & 100.1 & 100.1 & \multirow{3}{*}{100.1} \\
\hline 50\%_02 & 672.90 & 1155954 & 0.04984 & 0.05438 & 100.1 & 100.0 & \\
\hline 50\%_03 & 673.11 & 1158198 & 0.04986 & 0.05449 & 100.2 & 100.2 & \\
\hline 70\%_01 & 1018.65 & 1753515 & 0.07545 & 0.08249 & 100.3 & 100.3 & \multirow{3}{*}{100.0} \\
\hline 70\%_02 & 1018.42 & 1746671 & 0.07544 & 0.08217 & 99.9 & 99.9 & \\
\hline 70\%_03 & 1016.46 & 1744562 & 0.07529 & 0.08207 & 100.0 & 100.0 & \\
\hline 100\%_01 & 1349.09 & 2292178 & 0.09993 & 0.10783 & 98.9 & 99.0 & \multirow{3}{*}{98.6} \\
\hline 100\%_02 & 1348.20 & 2281190 & 0.09987 & 0.10732 & 98.5 & 98.5 & \\
\hline 100\%_03 & 1347.63 & 2272375 & 0.09982 & 0.10690 & 98.2 & 98.2 & \\
\hline 125\%_01 & 1686.17 & 2867979 & 0.1249 & 0.13492 & 99.1 & 99.1 & \multirow{3}{*}{98.9} \\
\hline 125\%_02 & 1685.31 & 2856118 & 0.12484 & 0.13436 & 98.7 & 98.7 & \\
\hline 125\%_03 & 1685.91 & 2866778 & 0.12488 & 0.13487 & 99.0 & 99.0 & \\
\hline 150\%_01 & 2015.68 & 3400552 & 0.14931 & 0.15998 & 98.3 & 98.3 & \multirow{3}{*}{98.2} \\
\hline 150\%_02 & 2023.69 & 3406155 & 0.1499 & 0.16024 & 98.0 & 98.0 & \\
\hline 150\%_03 & 2021.14 & 3411601 & 0.14971 & 0.16050 & 98.3 & 98.3 & \\
\hline
\end{tabular}

Table 9: 
Citation: Naveen Kumar Reddy G, Rajendra Prasad VVS, Maiti NJ, Nayak D, Prashant Kumar M (2011) Development and Validation of a Stability Indicating UPLC Method for Determination of Moxifloxacin Hydrochloride in Pharmaceutical Formulations. Pharm Anal Acta 2:142. doi:10.4172/2153-2435.1000142

Page 8 of 10

\begin{tabular}{|c|c|c|c|c|c|c|c|c|}
\hline \multicolumn{9}{|c|}{ Moxifloxacin Analytical Method Validation-Assay } \\
\hline \multicolumn{3}{|c|}{ Method Parameter } & \multicolumn{6}{|l|}{ Method Precision } \\
\hline \multirow{2}{*}{$\begin{array}{l}\text { Std. wt. \& } \\
\text { Dilution }\end{array}$} & 44.02 & 5 & Tablet Wt. & \multirow[t]{2}{*}{$\begin{array}{l}\text { Spl. wt. \& } \\
\text { Dilution }\end{array}$} & $\begin{array}{l}\text { Wt. of sample } \\
\text { taken }\end{array}$ & 5 & $\begin{array}{l}\text { Label claim } \\
(\mathrm{mg})\end{array}$ & 400 \\
\hline & 100 & 20 & 675.01 & & 200 & 200 & Potency (\%) & 98.8 \\
\hline \multicolumn{4}{|c|}{ Molecular factor for Moxifloxacin } & 0.917 & & & & \\
\hline Std. No. & Standards & USP Tailing & $\begin{array}{l}\text { Weight of sample } \\
\text { taken }\end{array}$ & Area of sample & Assay \% & Average (\%) & STDEV & $\%$ RSD \\
\hline 1 & 2310915 & 1.54 & 1353.34 & 2337254 & 101.04 & \multirow{7}{*}{100.4} & \multirow{7}{*}{0.61837} & \multirow{7}{*}{0.62} \\
\hline 2 & 2290693 & 1.54 & 1351.89 & 2321427 & 100.46 & & & \\
\hline 3 & 2300684 & 1.54 & 1358.15 & 2317128 & 99.81 & & & \\
\hline 4 & 2300777 & 1.54 & 1353.97 & 2341249 & 101.16 & & & \\
\hline \multirow[t]{2}{*}{5} & 2300755 & 1.54 & 1355.02 & 2324067 & 100.34 & & & \\
\hline & & & 1356.39 & 2310208 & 99.64 & & & \\
\hline Average & 2300765 & 1.54 & 1354.79 & 2325222 & 100.41 & & & \\
\hline STDEV & 7149.73 & 0.00 & \multirow{2}{*}{ Limits } & \multirow{2}{*}{\multicolumn{5}{|c|}{$\%$ RSD of 6 replicate injections is not more than 2}} \\
\hline \%RSD & 0.31 & 0.0 & & & & & & \\
\hline
\end{tabular}

Table 10:

Moxifloxacin Analytical Method Validation-Assay

Method Parameter

Intermediate Precision

\begin{tabular}{|c|c|c|c|c|c|c|c|c|}
\hline \multirow{2}{*}{$\begin{array}{l}\text { Std. wt. \& } \\
\text { Dilution }\end{array}$} & \multirow{2}{*}{\begin{tabular}{|l|}
44.13 \\
100 \\
\end{tabular}} & \multirow{2}{*}{$\begin{array}{l}5 \\
20\end{array}$} & \multirow{2}{*}{$\begin{array}{l}\text { Tablet Wt. } \\
675.01\end{array}$} & \multirow{2}{*}{$\begin{array}{l}\text { Sample wt. \& } \\
\text { Dilution }\end{array}$} & $\begin{array}{l}\text { Wt. of sample } \\
\text { taken }\end{array}$ & 5 & $\begin{array}{l}\text { Label claim } \\
(\mathrm{mg})\end{array}$ & 400 \\
\hline & & & & & 200 & 200 & Potency (\%) & 98.8 \\
\hline \multicolumn{4}{|c|}{ Molecular factor for Moxifloxacin } & 0.917 & & & & \\
\hline Std. No. & Standards & $\begin{array}{l}\text { USP } \\
\text { Tailing }\end{array}$ & $\begin{array}{l}\text { Wt. of sample } \\
\text { taken }\end{array}$ & $\begin{array}{l}\text { Area of } \\
\text { sample }\end{array}$ & Assay \% & $\begin{array}{c}\text { Average } \\
(\%)\end{array}$ & STDEV & $\%$ RSD \\
\hline 1 & 2315498 & 1.52 & 1351.91 & 2303175 & 99.22 & \multirow{7}{*}{99.4} & \multirow{7}{*}{0.388} & \multirow{7}{*}{0.39} \\
\hline 2 & 2302693 & 1.52 & 1360.40 & 2318575 & 99.26 & & & \\
\hline 3 & 2314434 & 1.52 & 1355.75 & 2314650 & 99.43 & & & \\
\hline 4 & 2321577 & 1.52 & 1353.39 & 2305262 & 99.20 & & & \\
\hline 5 & 2330688 & 1.52 & 1352.51 & 2325271 & 100.13 & & & \\
\hline 6 & & & 1356.55 & 2306776 & 99.03 & & & \\
\hline Average & 2316978 & 2 & 1355 & 2312285 & 99.38 & & & \\
\hline STDEV & 10269.35 & 0.00 & \multirow{2}{*}{ Limits } & \multirow{2}{*}{\multicolumn{5}{|c|}{$\%$ RSD of 6 replicate injections is not more than 2}} \\
\hline \%RSD & 0.4 & 0.0 & & & & & & \\
\hline
\end{tabular}

Table 11:

\begin{tabular}{|c|c|c|c|c|c|c|c|}
\hline \multicolumn{8}{|c|}{ Moxifloxacin Analytical Method Validation-Assay } \\
\hline \multicolumn{2}{|c|}{ Method Parameter } & \multicolumn{6}{|c|}{ Method \& Intermediate Precision combined } \\
\hline \multicolumn{2}{|c|}{ Method Precision } & \multicolumn{2}{|c|}{ Intermediate Precision } & \multirow[b]{2}{*}{ Difference } & \multirow[b]{2}{*}{$\begin{array}{l}\text { Average of both Method \& } \\
\text { Intermediate precision }\end{array}$} & \multirow[b]{2}{*}{$\begin{array}{l}\text { STDEV of both Method \& } \\
\text { Intermediate precision }\end{array}$} & \multirow[b]{2}{*}{$\begin{array}{l}\text { \%RSD of both Method \& } \\
\text { Intermediate precision }\end{array}$} \\
\hline S.No. & $\%$ Drug content & S.No. & $\%$ Drug content & & & & \\
\hline 1 & 101.04 & 1 & 99.2 & 1.8 & \multirow{6}{*}{99.9} & \multirow{6}{*}{0.730} & \multirow{6}{*}{0.73} \\
\hline 2 & 100.46 & 2 & 99.3 & 1.2 & & & \\
\hline 3 & 99.81 & 3 & 99.4 & 0.4 & & & \\
\hline 4 & 101.16 & 4 & 99.2 & 2.0 & & & \\
\hline 5 & 100.34 & 5 & 100.1 & 0.2 & & & \\
\hline 6 & 99.64 & 6 & 99.0 & 0.6 & & & \\
\hline
\end{tabular}

Limits: Overall RSD when compared with Method precision should be not more than $2 \%$.

Table 12: 
Citation: Naveen Kumar Reddy G, Rajendra Prasad VVS, Maiti NJ, Nayak D, Prashant Kumar M (2011) Development and Validation of a Stability Indicating UPLC Method for Determination of Moxifloxacin Hydrochloride in Pharmaceutical Formulations. Pharm Anal Acta 2:142. doi:10.4172/2153-2435.1000142

Page 9 of 10

\begin{tabular}{|c|c|c|c|c|c|}
\hline \multicolumn{6}{|c|}{ Moxifloxacin Analytical Method Validation-Assay } \\
\hline \multicolumn{3}{|c|}{ Method Parameter } & \multicolumn{3}{|c|}{ Robustness } \\
\hline \multicolumn{3}{|c|}{ Change in Flow Rate $(0.25 \mathrm{~mL} / \mathrm{min})$} & \multicolumn{3}{|c|}{ Change in Flow Rate $(0.35 \mathrm{~mL} / \mathrm{min})$} \\
\hline Std. No. & Standards & USP Tailing & Std. No. & Standards & USP Tailing \\
\hline 1 & 2743760 & 1.55 & 1 & 1973875 & 1.49 \\
\hline 2 & 2774673 & 1.55 & 2 & 1943344 & 1.49 \\
\hline 3 & 2740829 & 1.55 & 3 & 1960245 & 1.49 \\
\hline 4 & 2732432 & 1.55 & 4 & 1952056 & 1.49 \\
\hline 5 & 2734277 & 1.55 & 5 & 1958542 & 1.49 \\
\hline Average & 2745194 & 1.55 & Average & 1957612 & 1.49 \\
\hline STDEV & 17118.49 & 0.00 & STDEV & 11255.31 & 0.00 \\
\hline \%RSD & 0.62 & 0.0 & $\%$ RSD & 0.57 & 0.0 \\
\hline \multicolumn{3}{|c|}{ Change in pH of Mobile Phase(1.6) } & \multicolumn{3}{|c|}{ Change in pH of Mobile Phase(2.0) } \\
\hline Std. No. & Standards & USP Tailing & Std. No. & Standards & USP Tailing \\
\hline 1 & 2271424 & 1.49 & 1 & 2263481 & 1.53 \\
\hline 2 & 2252217 & 1.49 & 2 & 2258739 & 1.53 \\
\hline 3 & 2249439 & 1.49 & 3 & 2276006 & 1.53 \\
\hline 4 & 2244184 & 1.49 & 4 & 2272593 & 1.53 \\
\hline 5 & 2241573 & 1.48 & 5 & 2276184 & 1.53 \\
\hline Average & 2251767 & 1.49 & Average & 2269401 & 1.53 \\
\hline STDEV & 11762.64 & 0.00 & STDEV & 7882.71 & 0.00 \\
\hline$\%$ RSD & 0.52 & 0.3 & $\%$ RSD & 0.35 & 0.0 \\
\hline \multicolumn{3}{|c|}{ Change in Org Phase Composition (90\%) } & \multicolumn{3}{|c|}{ Change in Org Phase Composition (110\%) } \\
\hline Std. No. & Standards & USP Tailing & Std. No. & Standards & USP Tailing \\
\hline 1 & 2311223 & 1.43 & 1 & 2265737 & 1.53 \\
\hline 2 & 2313683 & 1.43 & 2 & 2269570 & 1.53 \\
\hline 3 & 2305552 & 1.43 & 3 & 2290266 & 1.53 \\
\hline 4 & 2315524 & 1.43 & 4 & 2291368 & 1.53 \\
\hline 5 & 2306395 & 1.43 & 5 & 2290691 & 1.53 \\
\hline Average & 2310475 & 1.43 & Average & 2281526 & 1.53 \\
\hline STDEV & 4393.90 & 0.00 & STDEV & 12742.53 & 0.00 \\
\hline \%RSD & 0.19 & 0.0 & \%RSD & 0.56 & 0.00 \\
\hline
\end{tabular}

Table 12:

chromatographic conditions. The results are tabulated in (Table 13).

\section{Calculation:}

\%Assay:

$$
{ }_{\text {As }}^{\text {At }}{ }_{100}^{\text {Ws }} \mathrm{X}_{20}^{5} \mathrm{X} \underset{\mathrm{Wt}}{200} \mathrm{X}{ }_{5}^{200} \mathrm{X} \underset{100}{\mathrm{P}} \mathrm{X} \underset{\mathrm{L}}{\mathrm{MF}=}
$$

Where

At=Area of test solution; $\mathrm{P}=$ Potency of Moxifloxacin $\mathrm{HCl}$ Working Std.on as is basis

As=Area of standard solution; Avg. Wt. =Avg. Wt. of 20 tablets

Ws=Weight of standard taken; LC=Label claim of the tablet as Moxifloxacin
$\mathrm{Wt}=$ Weight of two tablets; $\mathrm{MF}=$ Molecular Factor for Moxifloxacin (0.917)

\section{Conclusion}

The reported UPLC method was proved to be simple, rapid with a runtime of $3 \mathrm{~min} \&$ reproducible. The validation data indicates good specificity, precision, accuracy \& reliability of the method. The developed method has many advantages like isocratic mode of elution, easy sample preparation, short run time and can be used for routine quality control analysis of Moxifloxacin formulations.

\section{References}

1. UPLC ${ }^{\mathrm{TM}}$ : An Introduction and Review Michael E. Swartz Waters Corporation Milford, Massachusetts, USA

2. FDA Guidance for Industry. Analytical Procedures and Methods Validation 
Citation: Naveen Kumar Reddy G, Rajendra Prasad VVS, Maiti NJ, Nayak D, Prashant Kumar M (2011) Development and Validation of a Stability Indicating UPLC Method for Determination of Moxifloxacin Hydrochloride in Pharmaceutical Formulations. Pharm Anal Acta 2:142. doi:10.4172/2153-2435.1000142

Page 10 of 10

(draft guidance), August 2000.

3. Vandana, Alok Kumar Chaudhary (2010) AJPSP 1:1, November 15, 74-84.

4. www.drugbank.ca/drugs/DB00218

5. www.chemblink.com
6. Kumudhavalli Manni Venkatachari,Chidambaram Saravanan, Rama Subbaiah, Balasundaram Jayakar (2010) IRJP 1(1) 333-336.

7. Dhumal DM, Shirkhedkar AA, Surana SJ (2011) Der Pharmacia letter 3: 453456.

8. Validation of Analytical Procedures: Text And Methodology Q2(R1). 